CHAPTER THREE

\title{
AUTHORSHIP, AUTHORITY AND ALCHEMICAL VERSE
}

\section{Medieval Authorship and Alchemica}

What is an author? This question, firmly associated with Foucault in the minds of scholars today, presented itself to writers and readers in different contexts a millennium ago. ${ }^{1}$ The written culture of the earlier Middle Ages was based on an original notion of God as the ultimate originator of the Creation and Biblical texts. In this sacred context,

writings of an auctor contained, or possessed, auctoritas in the abstract sense of the term, with its strong connotations of veracity and sagacity [...]. [The] thinking we are investigating seems to be circular: the work of an auctor was a book worth reading; a book worth reading had to be the work of an auctor. ${ }^{2}$

Human, if still divinely inspired, writers were introduced to the world of writing through learned commentaries and prologues; they contributed exegetical insights and original thought to the written oeuvre of their time, within the framework of a divine Creation. Ancient writers were established as authorities for specific scholarly disciplines in the high Middle Ages, like Galen for medicine. Here, too, text and author became synonymous. "When medieval writers allude to Augustine or Ovid, the chief association that these authoritative names conjure up is not that of an inspired figure whose genius informs certain texts but that of the texts themselves."

Concepts of authorship and attribution practices relating to the corpus around the "Verses upon the Elixir" are distant relatives of the Scriptural tradition in some respects. Latin alchemica modelled on, translated from or referring to the older Islamic and Greek traditions showed an early tendency to use attributions in order to add connotations of ancient wisdom to a text. Paul of Taranto's thirteenth-century ascription of his own, clearly scholastic Summa perfectionis to Geber is a perfect example of this practice. ${ }^{4}$

\footnotetext{
1 Foucault, "What is an Author?"; based on a lecture, this was originally published in 1969.

2 Minnis, Medieval Theory, 39, 9.

3 Wogan-Browne et al., Vernacular, 5.

4 See Newman, Summa Perfectionis.
} 
Alchemical authors elevated by medieval attribution included the real, mythical and Biblical (Rhazes, Maria and Moses) as well as contemporary writers. In the fifteenth century, canon of Bridlington George Ripley wrote alchemical verse under his own name; his status as Middle English alchemical poet was established soon afterwards and increased with pseudonymous writings - a status which would also affect the perpetuation of the anonymous corpus around the "Verses upon the Elixir" in later centuries.

Yet the concept of authorship applicable to Middle English poetry, and thence alchemical poetry, differs from the Scriptural and canonical model to some extent. Indeed, the Middle English literary verse tradition is largely anonymous. Only longer works like the Confessio Amantis seem to "warrant autobiographical mise en scène". Short courtly love poems circulated largely without attribution; and where an ascription occurred, it often became synonymous with the authority of the poem itself. ${ }^{5}$ Similarly, alchemical poetry of fifteenth-century England rarely provoked consistent attribution. It shows an unwitting connection here to late medieval Fachliteratur, like books of secrets and craft manuals, which were conceived of as preserving knowledge that "was not referred back to canonical auctoritates, but was collective and anonymous". ${ }^{6}$ Overall, the act of authorial attribution for late medieval natural philosophical writings, particularly pragmatic alchemical writings, and even more so for alchemical poetry, was not a natural part of manuscript composition, and not necessarily expected by audiences, either.

Whenever they were recorded in manuscripts, authorial names occurred in various, vulnerable and ambiguous places on a manuscript page (in titles or colophons, appearing as characters or merely referred to in the texts themselves, or as references added by readers in the margins). Not marked as authorial in any of these positions these names could also indicate persons otherwise associated with a text or its contents. Attempts made as early as in the thirteenth century, in prologues to Scripture, to clear up similar confusions by means of textual organisation did not prove successful in all types of manuscripts. At the time when the corpus around the "Verses" first appeared in late medieval manuscripts the purpose and place of an attribution was still not conventionally fixed. ${ }^{7}$

${ }^{5}$ Boffey, Courtly Love, 62 and 65.

${ }^{6}$ Chartier, "Foucault's Chiasmus," 27.

7 Minnis, Medieval Theory, 156. See also Thomas, "Reading and Writing," 401; Thomas cites Peter Beal, "Shall I Die?”. The corpus' manuscripts very rarely provide textual markers ('[name] scripsit') for authors. 
The nature of alchemy and its writings added a further element of instability to attribution and authorship in alchemical manuscripts. Middle English recipes in particular reflected contemporary practices of alchemy and writing, both of which were riddled with experimentation and change. ${ }^{8}$ Consequently, readers' beliefs in authority and authorship varied with each copy and reading experience. Theoretically, in the likely case that an experiment based on a recipe did not produce the promised result, alchemists could either adjust the text, leave it unchanged but interpret it differently, or dismiss its authority, whether named or not. Names of authors were added to or removed from manuscripts simultaneously, if not always accordingly. For Middle English alchemical poetry, vernacular recipe texts written with an eye to practicability rather than named authority, anonymous circulation constituted a viable and commonly practised option; the vast number of anonymously recorded alchemical verse even in recent catalogues testifies to this. ${ }^{9}$ As obvious from the surviving witnesses of texts from the corpus around the "Verses", anonymity did not preclude the popularity of a recipe text.

The notion of pseudonymous writing merits special consideration in this context. To the modern reader, pseudonymous authorship seems to indicate that there is something amiss with the veracity of an attribution. Alchemical readers, however, many of them copyists themselves, knew of the common attribution practices of late medieval writing and had different expectations towards the function and meaning of an ascription. ${ }^{10}$ For them, the truth value of an attribution depended on a shared belief in authorship in its general sense of origination, and in the case of alchemica, also the school of thought, especially widely conceived in the case of the Lullian approach to alchemy. ${ }^{11}$ The fact that attributions varied between different copies of the same text did not challenge the perception of a text per se. It just added to the task of interpretation required from a learned user of alchemical textsone that certainly did not affect the efficacy of the recipe described in the text.

8 See Chapters 1 and 2 above.

${ }^{9}$ DIMEV; Voigts and Kurtz, Scientific and Medical Writings and others.

${ }_{10}$ Minnis, Medieval Theory, 15-29; and Bonner, "Chaucer Apocrypha," esp. 473-476. For a discussion of authorship and truth, see Kane, Piers Plowman, esp. p. 6, and Minnis, Medieval Theory, 21 and 47. The analysis of attributions for the "Verses upon the Elixir" below will provide further evidence on this subject.

${ }^{11}$ Long, Openness, 145. Lull was referenced in the Introduction and Chapter 1 above, and will feature again in the ascription history of the "Verses" below. 
By the end of the period considered here, printing and publication increasingly determined the world of writing and the concept of authorship, with a tendency towards its modern form. ${ }^{12}$ The corpus around the "Verses" and its reception were also affected by these developments. As contemporary and ancient authors' names graced the title pages of printed books, the "Verses upon the Elixir" and some associated texts, too, entered printed publication and secondary literature with a fixed authorial name. A novel, Latin prose incarnation of the "Verses upon the Elixir" was absorbed into collected works of George Ripley in the seventeenth century; eighteenthcentury tomes like Zetzner's Theatrum Chemicum included "Alumen de Hispania" among their items; and Francis Barrett's typically nineteenthcentury publication, The Lives of Alchemystical Philosophers, paraphrased the "Verses" and other works whose authorial and other origins are more questionable than his prose suggests. ${ }^{13}$ Around the same time, as indicated previously, collectors of manuscripts including Elias Ashmole and Sir Mathew Hale investigated the authorial origins of these texts. Authorship was now considered a true reflection of origins.

\section{Attributing the "Verses UPON the EliXiR"}

Authorial attributions for the poem "Verses upon the Elixir" provide a concrete example of motivations and implementations of attribution in Middle English alchemical poetry. ${ }^{14}$ Generally, the supposed authorship of the "Verses" alone is more diverse, less stable and comparatively older than Pearce the Black Monk's acknowledgement in the Theatrum Chemicum Britannicum would suggest. ${ }^{15}$ Copyists of the "Verses" may generally have asked themselves who wrote the poem throughout its transmission, but only few of them proposed an answer in the form of an authorial attribution (Table III). Considered in connection with the textual history

\footnotetext{
12 On early modern English alchemical publications see Kassell, "Secrets". On manuscript and print McKitterick, Print; on scientific topics in print Timmermann, "Introduction".

${ }^{13}$ Zetzner, Theatrum Chemicum, Vol. 5, 497-498; Ripley, Opera, 314-322; Barrett, Alchemystical Philosophers, 298-299 (paraphrase); based upon the last was Waite, Alchemystical Philosophers, albeit without inclusion of Pearce the Black Monk or the "Verses upon the Elixir".

${ }^{14}$ A thorough study of attributions across the corpus around the "Verses" has shown that practices applied to this individual poem mirror those occurring in the wider corpus (Timmermann, Circulation and Reception, Chapter 5); the focus on the "Verses" in this chapter is pragmatic and exemplary in nature.

$15 T C B, 269,473$ and 487 .
} 
Table III: Ascriptions for the "Verses upon the Elixir"

\begin{tabular}{|c|c|c|c|}
\hline Date & $M S$ & Author & Title \\
\hline$\sim 155^{\circ}$ & TCD 389 & Chaucer & "The verses" \\
\hline $1550-1600$ & BL Sloane 3667 & Raymonde Lully & $\begin{array}{l}\text { "a philosophor spekyth thus" } \\
\text { ["1. Raymonde Lully"] }\end{array}$ \\
\hline$\sim 1575$ & Bod Ashmole 1485 & $\begin{array}{l}\text { Thomas Norton \& "an } \\
\text { Unknowen aucthor" }\end{array}$ & $\begin{array}{l}\text { "An Allegorye supposed to be } \\
\text { made by Thomas Norton" \& } \\
\text { "Verses of an Unknowen } \\
\text { aucthor" }\end{array}$ \\
\hline s. $x v i$ & Bristol * & Norton & $*$ \\
\hline s. $x v i$ & Leconfield 99 * & Norton & $*$ \\
\hline s. $x v i$ & BL Sloane 3688 & Arnoldus de Villa Nova & $\begin{array}{l}\text { "De magno opere of Arnoldus } \\
\text { de Villa Nova" }\end{array}$ \\
\hline s. $x v i$ & Bod Ashmole 1490 & Maria & "Another. Maria" \\
\hline $1603-1625$ & Bod Ashmole 1445 I & $\begin{array}{l}\text { (canc. Arnoldi de uilla } \\
\text { noua) Chaucer }\end{array}$ & $\begin{array}{l}\text { "Elixer Arnoldi de uilla noua" \& } \\
\text { "A pracktike" }\end{array}$ \\
\hline s. $x v i i$ & GUL Ferguson 229 & "Pierce ye black Monck." & [“Thus"] \\
\hline s. $x v i i$ & Edinburgh ERG/1/4 & Pearcye & "Pearcye" \\
\hline s. $x v i i$ & KCC Keynes 42 & Pearce the black Monck & $\begin{array}{l}\text { "Pearce the black Monck upon } \\
\text { ye Elixir" }\end{array}$ \\
\hline s. $x v i i$ & KCC Keynes 67 & "An vnknowen author" & $\begin{array}{l}\text { "An vnknowen author, vpon the } \\
\text { philosophers stone." }\end{array}$ \\
\hline mid-s. xvii & Bod Ashmole 1445 III & $\begin{array}{l}{[\text { Dr Flood], "Piearcie the }} \\
\text { Black Monke" }\end{array}$ & $\begin{array}{l}\text { "Veritas de terra orta est" \& } \\
\text { "Piearcie the Black Monke vpon } \\
\text { ye Elixir." }\end{array}$ \\
\hline
\end{tabular}

${ }^{*}$ MS lost ${ }^{16}$

[ ] attribution or title added in a later hand or ambiguous

of the "Verses upon the Elixir" (i.e., its transmission over time and stemma), this list of attributions is rather revealing. ${ }^{17}$ Only one fifth of the extant

${ }^{16}$ Ascription for Bristol MS recorded in Norton, Ordinall (introd. Holmyard), vi; for Petworth House Leconfield MS 99 in Royal Commission on Historical Manuscripts, Sixth Report, Appendix, s.v. item 99. Since the places and times of ascription vary considerably (either written by the original scribe together with the text of the poem or by a later reader; directly above a text or in the margins), the recorded names are not necessarily all intended to name authors; they might also refer to helpful literature or other associations in some cases.

17 The stemmata for the "Verses", as well as a list of manuscript witnesses, may be found with the poem's Edition in the Appendix (Diagrams VI and VII). 
copies (thirteen out of sixty-one) record an author's name; four fifths circulated anonymously.

The custom of attribution clearly emerges as a typically early modern one in the corpus, as numbers of attributions increase with time. Indeed, the temporal distribution of authorial names in the corpus around the "Verses upon the Elixir" mirrors that of the recording of other names (of owners, collectors and readers) discussed at the end of Chapter 2 above. But the patterns of attribution in the succession of copies through the centuries also indicate scribal spontaneity. Six of the recorded names occur in more than one copy, but never in an exemplar and its direct ancestor or descendant. The three listed attributions of the "Verses upon the Elixir" to Thomas Norton even apply to different versions of the text; the relevant manuscripts are neither related nor otherwise linked with each other through common sources (for texts from within or without the corpus) or ownership. Further, the copyists of two directly related manuscripts listed here made different choices of authorial attribution: the exemplar (Bod MS Ashmole 1490, a volume favouring ancient authorities) attributes the "Verses" to Maria; its copy (Bod MS Ashmole 1445, a collection of English alchemica in Ashmole's possession while he was compiling the Theatrum Chemicum Britannicum), attributes it initially to Arnold of Villanova, then amends the ascription to Chaucer. Here and elsewhere attributions seem to follow a compiler's tastes and perceptions, not a commonly agreed ascription or an exemplar's model.

Similarly disjointed patterns of attribution are observable throughout the corpus around the "Verses upon the Elixir", which remained, essentially, an anonymous body of texts. Its attributions were rarely so persistent or apposite that they defined a text up to the point of its preservation in print. ${ }^{18} \mathrm{Of}$ the three hundred surviving copies of the core corpus poems alone only eleven contain an explicit or implicit ascription. The only poem consistently associated with a poet's name is the "Mystery of Alchemists", which is marginal to the corpus but, as mentioned above, formed an established part of Ripley's attributed oeuvre. It is particularly noteworthy that the attribution of related prose texts ("Alumen de Hispania", "Thomas Hend" and "Terra Terrae Philosophicae") is disproportionately high and consistent. This may, indeed, be due to the Latin texts' coherence with Latin prose practices of

${ }^{18}$ See Chapter 1 for individual poems' attribution histories. For a general theory on the purposes of the ascriptions see Long, Openness, 145 . 
ascriptions, and their role in the international dissemination of texts. This point will be discussed in more detail in the two case studies at the end of this chapter.

The mixture of scribal spontaneity, deliberation, education and experience that constitutes the act of attribution in the corpus around the "Verses upon the Elixir" frames a pertinent question: by which criteria did these copyists choose an authorial name? Many of the attributions listed above (e.g. those to Raymond Lull and Arnold of Villanova, doctors of alchemical fame, and to mythical ancient alchemist Maria the Jewess) can be explained in terms of an author's popularity at the time of attribution, and his or her association with promising alchemical lore and recipes. Similarly, the abovementioned unrelated attributions to Thomas Norton seem appropriate, since Norton wrote his seminal Middle English alchemical poem "The Ordinal of Alchemy" around the time of the birth of the "Verses": copyists would have recognised the poems' parallels in genre, time of writing and style. The choice of Pearce the Black Monk as an author, however, is more puzzling. A literarily undistinguished character with no historical record other than his appearance in "Trinity", Pearce only adds his designation as a black, i.e. Benedictine monk, to the picture, which may have carried favourable connotations for those who used his as an authorial name. Furthermore, the "Verses upon the Elixir" were never attributed to the alchemist we now consider to be the household name of alchemical poetry, George Ripley - an indication that late medieval, early modern and modern concepts of alchemical authorship might differ considerably.

Geoffrey Chaucer's appearance in the list of authors of the "Verses upon the Elixir" illuminates the contemporary reception of the genre of alchemical poetry further. One of the attributions appears uncontested at the top of one copy of the poem (TCD MS 389 , written in the mid-sixteenth century); ${ }^{19}$ the other, already mentioned above, amends an original Chaucer attribution to one to Arnold of Villanova (Bod MS Ashmole 1445, dating from the beginning of the seventeenth century). In both cases it seems likely that the writers recognised certain literary qualities in the "Verses", a tone, style and vocabulary they associated with Chaucer's writings. The general Chaucer reception of the sixteenth century in particular was marked by a special appreciation of his 'learned' qualities, which also resulted in a significant

\footnotetext{
19 The attribution here refers to a set of texts and may not have extended to the "Verses upon the Elixir"; the argument of this chapter is not affected by this. Timmermann, "New Perspectives".
} 
addition of 'scientific' titles, mostly dating from the fifteenth century, to the Chaucer apocrypha: the "Treatise on the Astrolabe", "Canon's Yeoman's Tale", "Equatory of the Planets", and also the "Verses upon the Elixir" and "Lead". Their attributions to Chaucer overwhelmingly occur in alchemical, medical and scientific manuscripts, many of them containing texts from the corpus around the "Verses upon the Elixir". ${ }^{20}$ Since the contemporary perception of Chaucer as an author and scholar did not involve the distinction between the genres of literature and science, between poetic writings about alchemical themes and alchemical writings in poetic form, the Chaucer ascription for the "Verses" is not intended to emphasise the literary qualities it acknowledges implicitly. Instead, it intentionally places an originally anonymous but well-known late fifteenth-century alchemical poem in the wider-ranging oeuvre of the sixteenth-century persona that is the 'scientific' Chaucer.

With regard to the concept of anonymity for late medieval and early modern readers of alchemical texts, two points are noteworthy. Firstly, the corpus's early modern readers may have disagreed with a copyist's choice of author at times, but they never protested against a text's anonymity. And secondly, there are signs of an onset of reflection upon authors and authority in the late-sixteenth-century corpus around the "Verses", in the form of an attribution to 'an unknown author' (Bod MS Ashmole 1485). This note is written to mark a deliberate break in the middle of a copy of the "Verses upon the Elixir" otherwise attributed to Thomas Norton. In his desire to distinguish the first from the second half of the poem, the copyist thus made a positive statement about missing information. Upon closer inspection of the relevant manuscript it becomes clear that this is a habit of a particular compiler. The initial two parts of this manuscript, produced around 1575 , contain mainly Latin prose. The "Verses" appear in the third part of the volume, a compilation of alchemica English in origin or language, written by Theodore Gravius, Richard Napier's assistant. ${ }^{21}$ This third manuscript section begins with a list of alchemical authors (f. $1^{v}$ ) and accumulates copies of several of George Ripley's works as well as other well-known alchemical poems. In this respect this manuscript prefigures Elias Ashmole's editorial activities for the $T C B$ a few decades later. One of its items is entitled "Certayne verses of an uncertayne aucthor": a poem which further survives in two other copies, one

20 Information on MSS and Chaucer ascriptions was sourced from Voigts and Kurtz, Scientific and Medical Writings. See also Dunleavy, "Chaucer Ascription,” 3; Bonner, "Genesis”; and Aiken, "Vincent of Beauvais".

21 The manuscript, but not the part discussed here, is mentioned in Poole, "Theodoricus Gravius," 246, fn. 35. Gravius was introduced in the final part of Chapter 2 above. 
of which, written by Simon Forman, ascribes it to Arnold of Villanova (Bod MS Ashmole 1490). What, then, were the motivations for Gravius's 'negative' attributions? Within this compendium's context, they seem to be connected with the act of manuscript compilation. The third section of the manuscript is presented as a collection of Ripleiana with ancillary, related texts. For this purpose, Gravius implicitly distinguished three categories: Ripleiana, poems by other well-known English authors, and anonyma. His penchant for a particular author's oeuvre (supported by the early modern taste for named works) generated his need to acknowledge each text's authorship. ${ }^{22}$ In the case of the "Verses upon the Elixir", his scrupulous categorisation prompted Gravius to bisect the poem into one part of (supposedly) wellknown, and one of unknown authorship. Finally, his choice to include the latter part of the "Verses" instead of truncating the text appears to be an acknowledgement of the textual tradition of the poem and indicates Gravius's acquaintance with the genre.

In conclusion, anonymity defines a well-respected part of fifteenthcentury English alchemical poetry. Especially in the early circulation of the "Verses upon the Elixir" attribution was very rare and an expression of personal, not commonplace, views. The integrity of the text and a wellproduced copy appear to have been most important for copyists in the production and use of an alchemical poem. Authors often just added grace notes to an anonymous tradition.

\section{Translations: Language, Genre And Authority}

While authorship did not equal authority in the late medieval period, and only few names of manuscript users were recorded over time, the genre of Middle English alchemical poetry itself offers a different, comparatively consistent approach to the issue of authoritativeness in the history of alchemy. Two pairs of texts from the corpus around the "Verses upon the Elixir" will illustrate the central role of genre in the communication of alchemical thought in the following two case studies. The first pair of texts (the Latin prose text "Alumen de Hispania" and its Middle English verse

\footnotetext{
22 See above; this development culminates, and becomes most visible, in the organisation of printed collections such as Gratarolus, Auriferae Artis, Zetzner, Theatrum Chemicum, and, a century later, Manget, Bibliotheca; and the publication of authorities' Opera (a continuation of the trend in the compilation of alchemical compendia described here) such as Raymond Lull's, Arnold of Villanova's and George Ripley's (see below).
} 
translation, "Richard Carpenter's Work", variant "Spain") represents the beginnings of the corpus and the rise of the English alchemical poem. The second pair (the Middle English alchemical poem "Verses upon the Elixir" and its Latin prose translation, "Terra Terrae Philosophicae") encapsulates the final period of the corpus' active manuscript circulation, and with it the institution of authorship as a badge of quality.

\section{1. "Richard Carpenter's Work": "Alumen de Hispania" in English Verse}

"Alumen de Hispania", a dialogue between Maria the Jewess and Aros (or: Aaron), a historically elusive 'philosopher' and student of the alchemical art, had transmitted instructions for the production of the philosophers' stone in Latin for more than a century when a fifteenth-century versifier decided to transform its recipe into Middle English verse to create "Richard Carpenter's Work", variant "Spain". As outlined above, both "Alumen de Hispania" and "Spain" circulated for more than two centuries in parallel, not in competition with each other, until "Spain" superseded its Latin prose original. Since the text remained unchanged in alchemical content, it must have been other qualities of either text that attracted audiences at different times: their authorship, linguistic forms and the genres of medieval Latin prose and Middle English poetry.

With regard to their authorship, "Alumen de Hispania" and "Richard Carpenter's Work" form exceptions in the corpus around the "Verses upon the Elixir". Both are associated with named authorities assigned during or soon after the period of their active circulation and reception. Their authors' cultural connotations and influence, however, have somewhat unique histories.

Maria the Jewess represented 'old alchemy' to medieval audiences. Evidence abounds of her alchemical repute in medieval written culture: she was supposed to have authored classical texts on alchemical lore and is mentioned in Thomas Norton's "Ordinal of Alchemy" and, in literature beyond the alchemical, in Ben Jonson's play "The Alchemist" in this capacity. ${ }^{23}$ Maria was also credited with the invention of some alchemical apparatus and the water bath, which is hence still known as 'bain marie. ${ }^{24}$ Yet, like that of the

23 "Will you believe in antiquity? Records?/ I'll show you a book where Moses, and his sister,/ And Solomon have written of the art;/ Ay, and a treatise penn'd by Adam [...]/O' the philosopher's stone". Jonson, The Alchemist, II, i, 80-83.

${ }^{24}$ Berthelot, Collection, 2: 26 and 37. 
alchemical Hermes, her fame was based on a confusing mythology. Maria was frequently mistaken for Miriam, the sister of Moses (even in "Spain", l. 9o), in accordance with the medieval belief that Moses was an inspired alchemist. ${ }^{25}$ Further, when referred to just as 'Maria', without a designator, she was not clearly distinguishable from the Virgin Mary, who features prominently in Western alchemist's invocations. By the turn of the seventeenth century, Maria's identity, and indeed the origin of "Alumen de Hispania", was frequently debated in alchemical circles, including a discussion by practitioner of alchemy and composer of emblems Michael Maier, physician to the Holy Roman Emperor Rudolf II. ${ }^{26}$ Maria's dialogue partner in "Alumen", Aros, was connected with a similar multitude of identities in early modern times, among them Horus, the Egyptian god, or Aaron, the Biblical figure (albeit without Biblical indications of alchemical expertise on his part). ${ }^{27}$ In "Alumen de Hispania", however, Maria refers "several times to God, in a style and manner that can best be characterized as those of Jewish piety". ${ }^{28}$ Further, Maria was always firmly connected with "Alumen" not by attribution, but thanks to its dialogue structure and her role as one of the speaking characters. A fifteenth-century manuscript even depicts Maria beside the text of "Alumen de Hispania", in appropriately ancient dress and headdress, and in a similar fashion to ancient Greek philosophers and sages drawn elsewhere in the volume. ${ }^{29}$ The text's authority was thus clearly anchored in Maria's (and Aros') mythical-historical personality.

The author supposed to have composed "Spain", Richard Carpenter, does not match Maria in repute or charisma. As mentioned previously, his modern association with the poem in its current title does not reflect the sparse number of attributions referring to him in early modern manuscripts; and Richard Carpenter's identity was never established outside of the text of the poem, in spite of Elias Ashmole's efforts to identify the author through other documents. ${ }^{30}$ The omission of his name from manuscript copies of the poem was certainly facilitated by its vulnerable location in the title line. Additionally, the act of translation that created this poem removed Maria from the

\footnotetext{
25 Moses appears as an adept in a Latin alchemical dialogue entitled "Allegoriae sapientium supra librum Turbae XXIX distinctiones". See Patai, Jewish Alchemists, 19 and 37, with reference to Gratarolus, Auriferae Artis; Zetzner, Theatrum Chemicum, 1: 467-479.

${ }^{26}$ Reidy, Thomas Norton's Ordinal, ll. 2657 and 2563. See Patai,Jewish Alchemists, 77, on its reception in Maier, Symbola Aureae Mensae.

${ }^{27}$ Patai, Jewish Alchemists, 60-80.

28 Patai, Jewish Alchemists, 71.

${ }^{29}$ Cambridge, St. John's College MS G. 14 (182), f. $6^{\text {r }}$.

30 See Chapter 1.
} 
text together with its dialogue structure. As a result, "Richard Carpenter's Work" circulated mostly anonymously.

Given this generally 'unauthorised' circulation of "Spain" and a stable association of "Alumen de Hispania" with Maria (and Aros) it is remarkable that "Spain" was no less popular than "Alumen" from the fifteenth century onwards. Moreover, copyists appear to have favoured the English poem over the Latin prose text once its transmission was firmly established in the sixteenth century. Even allowing for uneven survival patterns of manuscript witnesses, an interesting chiasmus appears in the second half of the sixteenth century: "Alumen de Hispania" reaches its lowest point of popularity at the exact time when "Spain" achieves its peak circulation. ${ }^{31}$

The textual form and presentation of the two texts appears to have been a decisive factor for the latter text's surge in popularity in the sixteenth century. In the broader, earlier medieval literary tradition, didactic dialogues represented a product of Latin scholastic literature which had become particularly popular with English audiences in the vernacular and in verse form. "Sidrak and Bokkus", a poetic scientific dialogue between a Christian philosopher and a heathen king originally composed in the thirteenth century and most revered in a Middle English verse translation of an Old French prose text, is just one of many examples of this genre; "The Argument of Morien and Merlin" another..$^{32}$ Didactic dialogues fulfilled a sophisticated pragmatic function for both fourteenth-century authors and audiences. They transported the reader into the text-in "Alumen de Hispania", Aros acts on behalf of the ignorant and doubtful alchemist wishing to learn the secrets of the art. They also ordered the text into sections (headed by Aros' questions) and information proper (here, the recipe for the philosophers' stone and its underlying theory, condensed into Maria's replies to Aros). Finally, didactic dialogues personified the authority of the text, here in the figure of Maria. For "Alumen de Hispania" the didactic dialogue thus provided a form, function and tradition appropriate to the customary Latin prose literature of its time.

By contrast, the transposition of "Alumen" into "Spain", from a didactic dialogue into a recipe, adapted the text to contemporary alchemical practitioners' tastes. It also affected the text's implications. "Spain" describes

31 Twelve full copies and substantial fragments of "Spain" survive from that period, but only three for "Alumen", two of which are vaguely dated for the entire period of the fifteenth and sixteenth centuries (see the list of manuscript witnesses provided with the Editions in the Appendix).

32 Burton, Sidrak and Bokkus; Grund, "Sidrak and Bokkus"; Taylor, "Morien and Merlin". 
materials and procedures (a recipe extracted from "Alumen") interspersed with theoretical information. It presents the recipe directly, without the mediation of a speaker, much less a dialogue between an explicit originator of the recipe and a user, and loses the association with Maria in the process. Although not original in content, "Spain" is an original composition in the medium of verse, indistinguishable in style and expression from the remainder of the corpus around the "Verses upon the Elixir". Its anticipated audience are, therefore, fifteenth-century readers used to navigating vernacular didactic poetry as well as alchemical laboratories, an audience whose education, literary experiences and expectations towards an alchemical text are different from that of "Alumen de Hispania". Interestingly, manuscripts incorporating "Spain" are, more often than not, compilations of English alchemica, not collections of traditional Latin texts. ${ }^{33}$

It is interesting to note here that "Alumen de Hispania" and "Richard Carpenter's Work" variant "Spain" eventually met on the ground of vernacular alchemica when "Alumen" was translated into English prose (and other vernacular languages) in the seventeenth century. The mechanics of translation, made more complex by this reversal of language and advance of genre, would merit further study. ${ }^{34}$ For current purposes, however, a few observations on the comparatively extensive scope of the English prose text will suffice. As mentioned above, "Spain" removed the optional and yet characteristic introduction of "Alumen", whereas its original rhetorical passages mimic elements typical of English alchemical poetry. But the seventeenthcentury English translation of "Alumen de Hispania" retains all textual elements of the Latin prose text yet echoes "Spain" in phrasing and expression. Due to the dilution of time and translation the early modern English texts of "Alumen de Hispania" and "Spain" would not have seemed to be related to anyone but the most careful reader:

Aros the Philosopher meeting with Miriam the prophetisse, sister of Moses, when he drew nigh to her, he honored her, \& said, oh Prophetesse I have heard very much concerning thee, viz: that thou dealbats the stone in one day, to whome Miriam answered, yes Aros, \& in part one day. [...]

Take allume of spaine white gume \& Red gume which is Kibrick of the Philosophers, \& their sol, \& greater tincture, \& conioyne gume, with gume, in true matrimony

"Alumen de Hispania" (English), introduction and excerpt (BL MS Sloane 3778, f. $100^{\mathrm{r}}$ )

${ }^{33}$ An early, prime example is TCC MS O.2.16, which dates from the fifteenth century. See James, Western Manuscripts, s.v. 'O.2.16'.

${ }^{34}$ Indicative of possible directions of research is Crisciani, "Aspetti". 
Of spayn take thou thy clere light

The redde gomme that is so bright

Of philosophers the sulphur vif

Callid golde withouten stryf

Of hyme drawe out a tyncture

And make a matrimony pure

"Spain", incipit

This late adaptation of "Alumen de Hispania" therefore further underlines the observation that "Spain" not merely translates, but transposes "Alumen" into the genre of English alchemical poetry.

How self-conscious the choice of medium might have been on behalf of "Spain"'s originator is an interesting conjecture, in spite of the poem's apparent success. A modern historian familiar with the apologies and defences of the English language published so copiously in early printed books might expect a similarly defensive attitude on behalf of alchemical writers of different ages, in anticipation of their audiences' possible scepticism towards their choice of medium. We already encountered an example of such a defensive passage in "Liber Patris Sapientiae" (TCB, 194-209, stanza 21) in a wordy, somewhat literary extension of the corpus around the "Verses". However, in the case of the pragmatic poetry that constitutes the core of the corpus this problem did not present itself. ${ }^{35}$ Instead, it seems that alchemical poetry in itself was a marker of reliability to late medieval and early modern readers. Verse had established itself as a customary vehicle for alchemical recipes within a few decades, just before "Spain" was composed. By the time "Richard Carpenter's Work" appeared in print in Elias Ashmole's Theatrum Chemicum Britannicum, and thereby became part of a leading printed collection of Middle English verse, its language and genre had become a merit, not a deficiency, even in the eyes of an early modern collector. ${ }^{36}$

In conclusion, "Alumen de Hispania" and "Spain" prove to be an interesting case of alchemical poetry gradually replacing didactic dialogue in function, repute and popularity. Moreover, it appears that the genre of alchemical poetry in itself carried authority. Early modern readers were not necessarily looking for authors but rather for rhymed recipes to advance their alchemical knowledge and practice. The implications of this histori-

35 " $[\mathrm{U}]$ ntil the very end of the seventeenth century, $[. .$.$] the didactic poem was much less$ self-conscious in both theory and practice, even though a good deal of it was being written and printed. [...] The abundance of vernacular didactic poetry [...] was the legacy of late medieval poetic practice, in which this kind of verse was taken for granted [...]. No defense [sic]—or definition—was necessary". Schuler, "Theory," 4.

36 TCB, "Prolegomena". 
cal development for historiography are as simple as they are profound: for late medieval and early modern history of alchemy and its craft and scholarly relations, a history of texts and genres captures an essential part of the spirit of sixteenth-century science.

\section{2. "Terra Terrae Philosophicae": \\ The "Verses upon the Elixir" in Neo-Latin Prose}

The Neo-Latin movement in text and scholarship, which coincided with the institution of print roughly a century after the introduction of verse just explored, considerably affected the circulation of the corpus around the "Verses upon the Elixir" in manuscript form. As for the previous establishment of Middle English verse as an accepted, popular medium of alchemical writing, this development was driven by both circumstances and audiences. Perhaps influenced by printers' endeavours to preserve a scientific and literary heritage in printed volumes, alchemical readers cultivated a new appetite for ancient and authoritative texts. This enthusiasm prompted the composition of texts based upon, imitating or pretending to be of an 'old' origin. ${ }^{37}$ In the case of the "Verses upon the Elixir" this new fashion for old texts involved a curious reinvention: the poem was translated from English verse into Latin prose, assigned with a fixed title ("Terra Terrae Philosophicae") and attributed to an author. This author was fifteenth-century English versifier George Ripley-an author we have encountered several times before, and whose repute as an alchemical authority for recipes like that presented in the "Verses" was growing in early modern continental Europe. ${ }^{38}$ "Terra Terrae Philosophicae" was created in the late sixteenth century and represents an exact translation of the "Verses", version A, complete with the "Exposition" and "Wind and Water". Rather than translating the poem into in Latin verse, which would be difficult but not impossible to achieve, "Terra Terrae" emulates Latin prose alchemica of previous generations. Similar Latinate compositions and reinventions would also define the printed compilations of alchemical texts in the late seventeenth and eighteenth centuries. ${ }^{39}$

${ }^{37}$ The term 'old', as used here, appears in historical manuscripts to indicate sources of merit (both manuscripts and texts) in the early modern period; the actual age of the sources is never specified further.

38 See Rampling, George Ripley's Alchemy, chapter 7 and ibid., "Transmission".

39 Some of these printed compilations were mentioned at the beginning of this chapter. 
"Terra Terrae Philosophicae", an appendage to the history of the "Verses upon the Elixir", represents the reversal of the history of "Alumen de Hispania" and "Spain": the removal of rhyme and the English language, and hence of the text's geographical, cultural and historical identity, in favour of a pan-scholarly language, a named authority and an associated, implied origin more ancient than the translation but possibly contemporaneous with the date of composition of the "Verses upon the Elixir". This act of translation (linguistic and cultural) invites a new investigation of the function and effects of genre, language and named authority on alchemical writing, now in a period defined by different ideals. Apart from a general appeal of Latinate alchemical knowledge, what recommended "Terra Terrae Philosophicae" to readers to merit its copious reproduction, its inclusion in printed collections, its persistent co-existence with the "Verses upon the Elixir" during the final decades of its active manuscript circulation, its translation into German and French and even its translation into English prose? ${ }^{40}$

The need for the composition of "Terra Terrae Philosophicae" and its popularity are matters worth pondering. Initially not circulated beyond the British Isles and rendering the text of the "Verses upon the Elixir" verbatim, "Terra Terrae" would not have increased the accessibility of the text to an Elizabethan audience. ${ }^{41}$ Its ascription to George Ripley, which occurs both early and persistently, seems to be the key element of value, both anticipated by the translator or early copyists of the text and readily accepted by its readership. This attribution to Ripley appears to have been as wilful an act as the translation was laborious. The overall purpose was likely the manufacture of another item for the pseudo-Ripleian oeuvre which would encourage circulation and, eventually, publication in print.

Notably, this use of a common knowledge about Ripley, his style, the alchemical content of his authentic and pseudoepigraphic work, vocabulary, choice of language and genre in the composition of texts was quite widespread in early modern England. Strengthened by more than a century of strong manuscript tradition, Ripley had become an emblem of late medieval alchemical wisdom by the turn of the seventeenth century. As mentioned previously, some texts from this 'Neo-Ripleian' body of works

40 An English prose rendition may be found in BL MS Sloane 3732, a seventeenth-century volume containing mainly items attributed to well-known personalities in the (then) recent history of alchemy.

41 Early surviving witnesses of the Latin prose version appear in manuscripts of English origin: BL MS Sloane 1842 and Bod MS Ashmole 1485, both from the second half of the sixteenth or turn of the seventeenth century. 
belong to the anonymous part of the corpus around the "Verses upon the Elixir": "Mystery of Alchemists" (included in Bale's bibliography of 1548 under Ripley's name); the "Short Work"; and the 'Ripley Scrolls' (attributed, among others, by Elias Ashmole in the Theatrum Chemicum Britannicum, who is otherwise so scrupulous in his verification of a text's authorship). ${ }^{42}$ By the mid-seventeenth century the addition of "Terra Terrae" to the Ripley apocrypha, too, had been fully accepted in English written culture. Pitts' famous bibliography of English authors then connected Ripley and "Terra Terrae Philosophicae" with each other in print; Combach's publication of "Terra Terrae" in 1649 together with Ripley's collected works would have raised only the eyebrows of very well-read, multilingual readers of manuscripts, i.e. of those who would have noticed the parallels to the "Verses upon the Elixir" and the conflict between the poem's anonymity and the prose text's attribution ${ }^{43}$ If any eyebrows were raised, they were raised in silence, as no written evidence to this effect survives. The reason why "Terra Terrae" proved to be successful in named print circulation thus appears to be a combination of its Latin language, the attribution to Ripley and its subsequent publication in print, which prompted further manuscript copies and translations to be produced. ${ }^{44}$

One point to consider in more detail is the reciprocity between manuscript and print in the seventeenth century. As printed and handwritten versions of the text co-existed, and manuscripts imitated print more and more often, readers' and copyists' beliefs about ascriptions were also influenced by the printed word. ${ }^{45}$ It is noteworthy in this context that the manuscripts in which the "Terra Terrae Philosophicae" appears, whether chosen over the "Verses" or independently, show a clear bias towards Ripleiana or named authorities. In the history of the corpus around the "Verses upon the Elixir", these manuscripts are not part of, but a supplement to, its manuscript circulation. Even those manuscripts which combine "Terra Terrae" with other items from the corpus have a clear agenda for their compilation, whether a focus on Ripleiana and Latin items (Bod MS Ashmole 1485 and GUL MS Ferguson 91) or, as is the case in one late manuscript (Edinburgh, Royal

\footnotetext{
${ }^{42}$ See Chapter 1 and the introductions to individual texts in the Editions below for bibliographical references.

43 Pitts, Relationum Historicarum. Ripley, Opera, 314-322.

${ }^{44}$ See Ripley, "Georgii Riplaei ... Schrifften".

45 It is likely, if not entirely demonstrable, that some of the late manuscript copies of "Terra Terrae Philosophicae" were copied from printed volumes. For a discussion of this context, see Chapter 5 below.
} 
College of Physicians MS ERG/1/4), the aim to preserve every item the collector could get his hands on. "Terra Terrae" is also often found in a curious mixture of periods and genres, among texts which are not clearly intended for the preparation of alchemical experiments but monuments of a philological or canonical tradition (as is the case in Vienna, Österreichische Nationalbibliothek Cod. 11133, a volume composed in a courtly setting at the beginning of the seventeenth century). ${ }^{47}$ As a result of these copying rationales, manuscripts containing "Terra Terrae Philosophicae" also point to an intended and actual readership different from that of the "Verses upon the Elixir" and early associated texts, and more akin to audiences for later printed compendia. Where "Spain" opened up a wider audience for the recipes also transmitted in "Alumen de Hispania", "Terra Terrae Philosophicae" deliberately defines a small, philologically inclined readership, a group set apart from the continually thriving reception of the "Verses" and other Middle English alchemical poems. This distinction between NeoLatin scholarly and English poetic craft manuscripts was also observed above for volumes containing "Alumen de Hispania" and "Spain".

It was probably because of this discrepancy in form and purpose, or rather the confusing lack of definition of either, that "Terra Terrae" often did not reach copyists who concentrated on materials from the core corpus around "Verses upon the Elixir". Elias Ashmole, for instance, considered "Terra Terrae" from a theoretical perspective only when he wrote his commentary on the "Verses"' authorship:

Ludovicus Combachius in his late Collections of some of Ripley's Workes, put this of Pearce the Black Monk's among them under the Title Terra Terrae Philosophicae; and publishes it as Ripley's: and withall that Tytle [Terrae Terrarum] which Pitts also gives to one of his Workes may seeme to insinuate this; But I conceive all are not Ripley's which walk under his Name, for questionlesse, many Pieces are (of late Tymes) fathered on him which he never wrote..$^{48}$

46 Examples of manuscripts not belonging to the corpus around the "Verses" in any other way are all rather slim volumes (of $75^{-143}$ folios each) of the seventeenth century; see the Handlist of Manuscripts (Bibliography) for details.

47 Vienna, Österreichische Nationalbibliothek Cod. 11133 roughly dates from 1604-16o8. On its composer, contacts and the compilation as means of social-professional proliferation see Hausenblasová and Purš, "Simon Thadeas Budek". Ripley is mentioned there (pp. 79-8o), but the copy of "Terra Terrae" or its role within this volume not discussed. I deduce its function within the codex's copies of Ripleian works from the entirety of the manuscript's contents and its compiler (Budek)'s table of contents on ff. $159^{\mathrm{r}}-190^{\mathrm{r}}$ "Index rerum et verborum in omnia opera venerabilis Canonici Domini Georgij Riplei Angli"; see also Rampling, "John Dee," esp. 501-502.

$48 T C B, 473$. 
Ashmole had always considered manuscripts a primary source of information, and he likely owned Bodleian Library MS Ashmole 1485, which contained both the "Verses" and a copy of "Terra Terrae" complete with Ripley's name, when he prepared the TCB. Yet apart from his concentration on English verse, his possible consequent blind spot for Latin prose and his doubt about the ascription, Ashmole may have had a practical reason to overlook the two texts' similarities: he did not include this particular manuscript in his preparations of his print publication. The relevant stemma shows that, if Ashmole indeed owned the volume at the time, he dismissed the copy of the "Verses" in Ashmole MS 1485 in favour of another for use in his edition for the Theatrum Chemicum Britannicum, and rightly so, as it is a unique, distinctive copy which does not represent an ideal, standard text suitable for Ashmole's philosophy behind the Theatrum. ${ }^{49}$ In the same step he may have dismissed the entire codex; there was no reason or opportunity for him to sift through its, or any other volume's, prose contents for his edition purposes. In other words, this copy of "Terra Terrae Philosophicae" and, significantly, others circulating with Ripley's name at the time, although probably not escaping his notice altogether, simply did not attract Ashmole's explicit attention. The "Verses upon the Elixir" were more attractive to him, and for most early modern men going before him.

A brief look at the circulation of the "Verses upon the Elixir" and its Latin translation in manuscripts testifies to the fact that, as demonstrated above, the poem did not depend on an authoritative name for popularity: no less than $5^{0}$ full copies and substantial fragments of the poem, but only eight copies of its Latin prose translation survive. ${ }^{50}$ More pertinently, copyists in possession of exemplars of both the "Verses upon the Elixir" and "Terra Terrae Philosophicae" chose not to reproduce them alongside each other and often decided in favour of the poem..$^{51}$ The poem remained the more popular of the two texts in English speaking countries until the end of their joint manuscript transmission towards the end of the seventeenth century; its prevalence appears to have remained in place even once the

49 Please see the stemma for the "Verses upon the Elixir", version B (Diagram VII) in the Appendix.

${ }^{50}$ See the manuscript witnesses listed with the Editions towards the end of this book for shelfmarks.

${ }^{51}$ For instance, the "Verses" in London MS Sloane 1842 served as exemplar for London MS Sloane 288 , but the copy of "Terra Terrae" was not transposed into the latter (see the stemma for version B of the "Verses", i.e. Diagram VII, and manuscript information and statistics for "Terra Terrae Philosophicae" here and in the Editions below). 
dissemination of "Terra Terrae" in print set in from the mid-seventeenth century onwards (the period following that considered here). Given that the ever-changing attribution of the "Verses", as outlined above, did not impede its popularity in the late sixteenth and early seventeenth centuries, one might well wonder whether its Latin prose translation would have been as successful as it was later on without the aid of Ripley and the print medium.

In sum, authorial ascription, translation and the transposition from prose into verse or vice versa had different effects on the circulation and reception of "Alumen de Hispania", "Spain", the "Verses upon the Elixir" and "Terra Terrae Philosophicae". Both translations discussed in this chapter reflect the fashions of their times. If we consider these case studies together with the patterns of ascription (or rather lack thereof) in the corpus around the "Verses" as a whole, it seems that authority in alchemical writing was not necessarily, and certainly not exclusively, expressed by way of attribution. The tendency to associate a named personality with authority increased in the later periods of the corpus' history. Where attributions do occur in the corpus they are as deliberate as a choice of genre and language. Most notably, genre was a significant carrier of authority. Medieval and early modern readers of alchemica understood verse and the Middle English language as indicators of value. For them, the promise of health, wealth and knowledge did not have a specific name but a distinct mode of expression. 